\title{
Exploration and Practice of Inquiry Teaching in Communication Theory Curriculum
}

\author{
Rong $\mathrm{Li}$ \\ School of Communication and Information Engineering, Xi'an University of Science and Technology \\ Xi'an, China, 710054 \\ cold3000@126.com
}

\begin{abstract}
Inquiry teaching can help understand and master knowledge and improve students' comprehensive ability to analyze and solve the problems. With "communication theory" as an example, the application of the inquiry teaching is explored. The practice results indicate that this method can give full play to the initiative of students and stimulate student's potential. Finally, the very good teaching effect is received.
\end{abstract}

Keywords-inquiry teaching model; communication theory; teaching practice in class

\section{INTRODUCTION}

"Communication theory" is an important professional basic course for communication engineering major, with many basic and complex knowledge structure. The traditional teaching method is that teachers impart knowledge by cramming method and students learn passively. Now, the new education viewpoint is put forward, which advocates active participation of students, their willingness of inquiry and operation. It aims to cultivate student's ability to collect and handle information, acquire new knowledge, analyze and solve problems, communicate and cooperate [1]. Obviously, the traditional teaching methods cannot meet the demand for modern higher education and the teaching effect is poor. Thus, the inquiry teaching advocates students to explore and discuss actively, teacher's imparting instead. The importance of knowledge acquisition is stressed. It not only helps students to master scientific conclusions but also encourages students to explore and master research methods, developing students' innovation spirit and scientific attitude during the inquiry process. From the current research situation of inquiry teaching around the word, the teaching method is at preliminary stage. The teaching strategies, reform mode, and assessment about inquiry teaching were discussed in some references, getting some experience and results both in theory and practice.

However, those theories did not aim at the "communication theory" curriculum and they cannot be applied to the practical teaching of this curriculum. Therefore, exploration of inquiry teaching in this course is a teaching way which is effective and advanced.

\section{DESIGN OF INQUIRY TEACHING}

\section{A. Bacic and goal}

During the inquiry teaching, teachers should reasonably design teaching content according to the syllabus and teaching schedule and propose some appropriate questions [4]. The fundamental theories and conclusions should be found out and mastered by students actively by data collection, thinking, analysis, discussion and exploring independently. Teachers are the designers of inquiry teaching and facilitators and organizers of the activity, while students are the subjects of inquiry teaching. Therefore, the teaching content should be classified in terms of the difficulty by teachers. The easy parts can be mastered by students independently. If some content is too difficult for students to handle, their potential should be realized by practice teaching.

\section{B. Design procedure}

The inquiry teaching consist of some basic component elements as follows. (1) Creating situation. The exploration situation should be provided by teachers and the inquiry activities can be developer by students. (2) Issue-oriented. Generally, the appropriate questions should be selected by teachers according to teaching content, while the evidence can be acquired by students to explain and evaluate the scientific questions. (3) Exploration and practice. The scientific questions can be answered by students in terms of various data evidence collected by themselves. (4) Communication and cooperation. Students should communicate with each other and discuss the various interpretations proposed by themselves. (5) Evaluation results. The evaluations should be done by teachers by analyzing various issues of students. Moreover, the class summary and introspection should be carried out. The different teaching procedure can be selected according to the nature of curriculum.

\section{DESIGN PROCESS AND IMPLEMENTATION}

\section{A. Design process}

For the specific inquiry topics of the curriculum, firstly students should detailed analyze the teaching contents and class type in terms of the teaching object and the facts of students. Secondly, appropriate teaching activities should be selected and organized to meet the demand for scheme design. 
Meanwhile, the function of the inquiry process should be realized by rational teaching situation, driving problem and effective evaluation methods. Finally, according to the specific exploration situation and practice experience, the activity types can be selected by teachers and the mode and construction of teaching activities can be determined. The design mode of inquiry teaching is shown in Figure 1.

\section{B. Implementation process}

The inquiry activities can be classified by the participation degree of subject of inquiry, which include the different inquiry process such as guidance, cooperation, self- study and so on. The organization structures are different according to the participation degree [3].

In this paper, aiming at the curriculum characteristics, the implementation process of inquiry teaching is Figure 2, which applies cooperation between students and teachers. Its structure is flexible. For a specific inquiry process, the structure can be changed or some partial structure can be used.

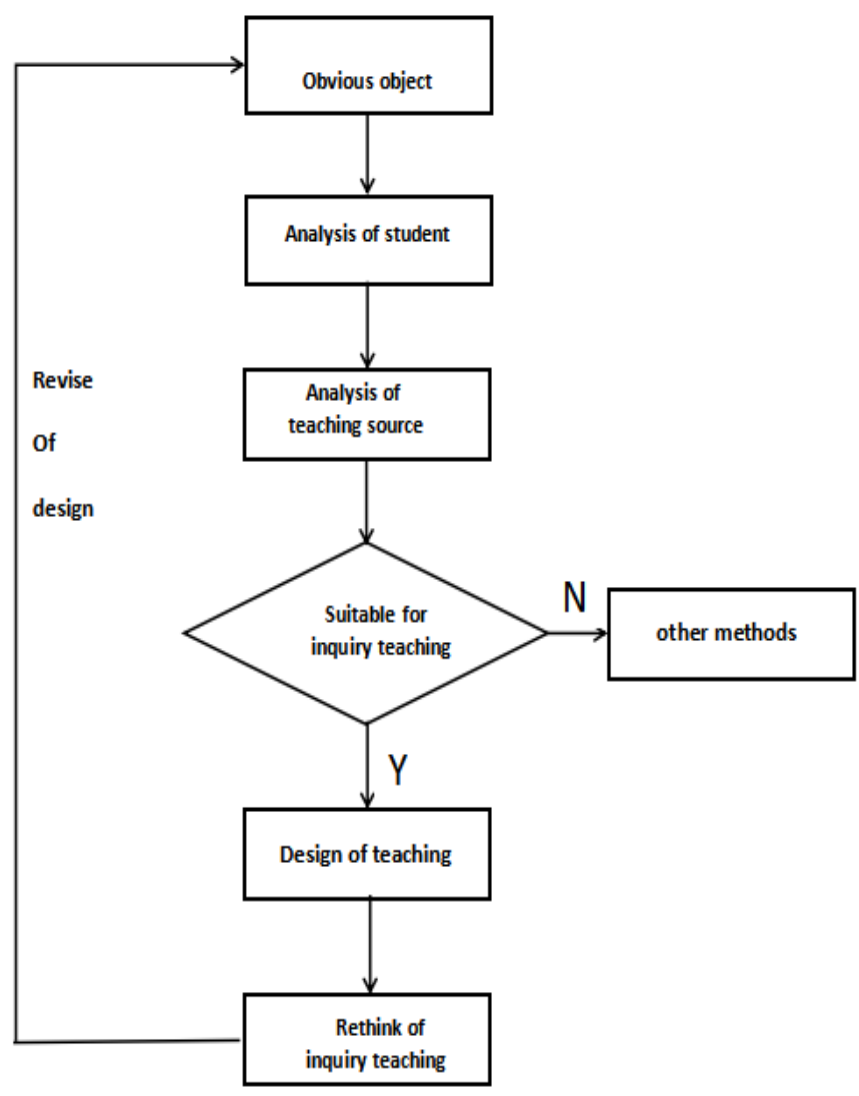

Fig. 1. Design mode of inquiry teaching

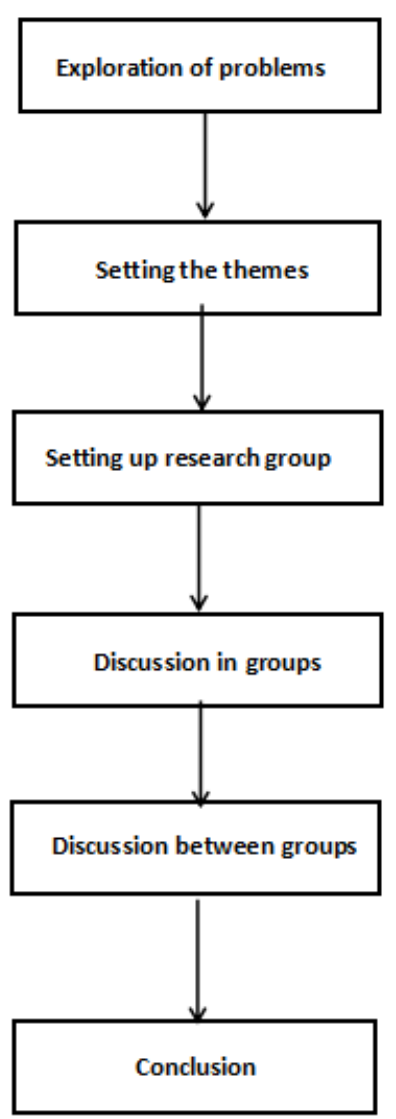

Fig. 2. Implementation process of inquiry teaching

The inquiry topic can be divided once the inquiry task is analyzed by teachers. Thus, the small topic will be produced, which is various relatively simple and interrelated. Firstly, aiming at the topic, various inquiry results should be discussed in the group. Then the communication should be launched among different groups. Finally, the conclusion can be get after the collaborative discussion between teachers and students.

\section{Summary and Assessment}

Teachers should encourage students to conclude for the exploration activity at the end of the inquiry teaching and evaluate the results. The assessment is the final part of the inquiry teaching. It is the end of this activity and next inquiry course may be breaded [5].

Therefore, the work of assessment is very important. To ensure the just and comprehensiveness of assessment diversification should be done about the evaluation dimension and methods. The "Three-dimension" mode can be adopted in inquiry teaching. One is that self-assessment and mutualevaluation among students may be carried out in terms of the standard, the other is the course of inquiry and to assessment results. Then the good mechanism of feedback, inspiration and punishment should be set up between two dimensions. To meet the demand teachers should monitor the inquiry course and grasp the evaluation scale in sight of prospect. Moreover, teachers should arrange all things and propose new inquiry 
issues. Then next inquiry activity man be appeared. Thus teachers should have more knowledge and stronger abilities.

After class teachers can leave some open and imaginative homework for students to inspire students' interests of autonomy, cooperation and inquiry. Teachers should objectively deal with the individual ability difference among students and assign the open homework moderately in groups [6].

\section{THE CASE ANALYSIS AND PRACTICE}

"Communication theory" is an important professional basic course for students who major in communication engineering, being a lot of comprehensive knowledge [2]. Now the traditional teaching methods cannot meet the demands. The inquiry teaching should be applied. In this paper, the teaching design and practice of the content of "PCM" and "modulation and demodulation" are carried out.

\section{A. Design process of "PCM"}

"PCM" is one of the key techniques in the communication system. It will be applied to some follow-up specialized courses. Therefore, the inquiry design in class is carried on about "PCM". The practice process is shown in Figure 3.

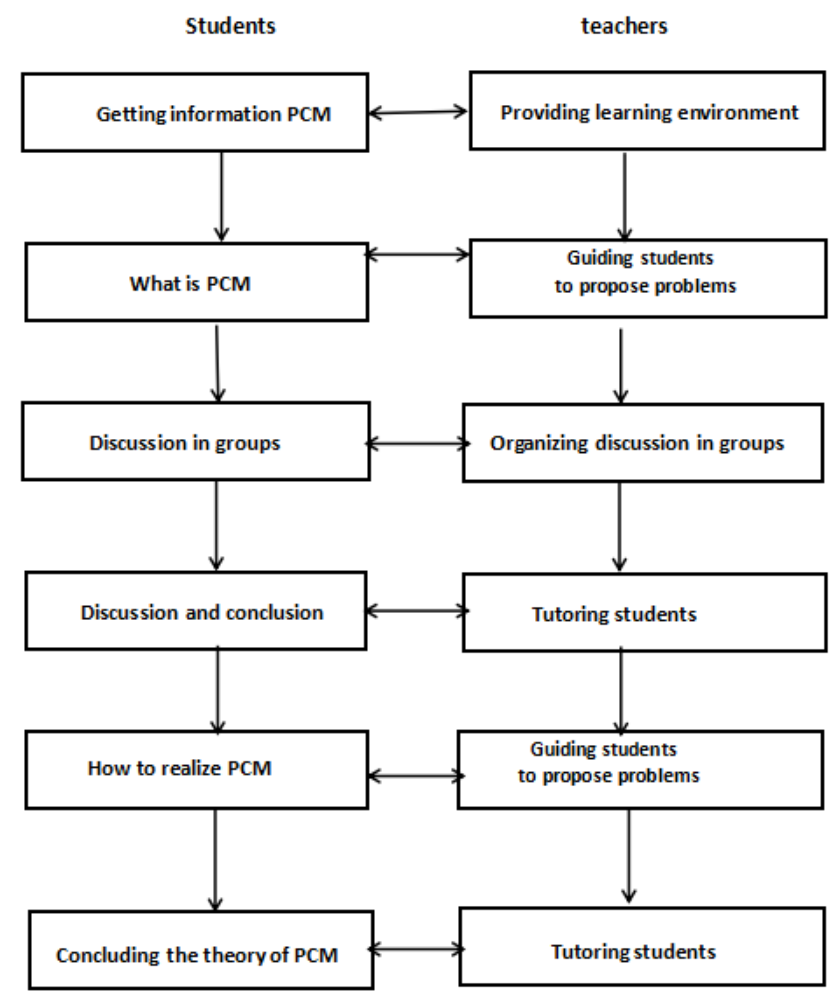

Fig. 3. Design of inquiry teaching on PCM

\section{B. Design process of "modulation and demodulation"}

"Modulation and Demodulation" is one of the fundamental and key techniques in this curriculum. So it is important to select this knowledge point as the inquiry topic. The specific implementation process is as follows.
1) Teaching target:

- The concept can be formed for students by the practical systems.

- Students can understand the basic theory.

2) Procedure of inquiry

- Students can increase their abilities to observe and describe experimental phenomena by the process of scientific research.

- Students can design, assess and debug by MATLAB or SIMULINK, while their abilities to learn actively may be increased.

- Students can experience the research process and recognize the basic methods of research by program or simulation results.

\section{3) Teaching method}

Cooperation inquiry method

4) Teaching process and implementation

- Creating situation: the transmission system of MSK modulation and demodulation should be demonstrated by multimedia animation and simulation by MATLAB

- Knowledge cognition: "modulation and demodulation" is one of the important techniques among those of communication. Now most of the communication system are frequency-band transmission. The modulation should be used at the sending end, correspoding demodulation at the receiving end.

- Group inquiry: Students can increase their abilities to observe and describe experimental phenomena by the process of scientific research. The issues of classification and implementation of modulation and demodulation should be discussed.

- Discussion in groups and between groups: students can stimulate the interest to learn communication techniques, experience the hardship and joys of scientific research and recognize the practicability and value of modern communication techniques.

- The conclusion can be got by cooperation between teachers and students.

- Effect assessment: The initiative of students can be improved obviously by the inquiry process of "modulation and demodulation".

\section{ADVANTAGES OF INQUIRY TEACHING}

There are many advantages about inquiry teaching. Inquiry is one of children's instincts. Inquiry is also human's life instinct throughout his life. It is an important path for students to understand and know the word. Students can really grasp knowledge which they learn them by themselves. Inquiry would help students to protect their curiosity and desire for knowledge. Thus their scientific spirit and attitude can be developed and they will know how to cooperate and communicate. Also they can learn to listen and reflect to help them get knowledge and information autonomously. Moreover students will experience so many things including frustration 
and failure, success and excitement. These experiences will help them really understand the nature of science and the significance of science.

\section{CONCLUSION}

The inquiry teaching can stimulate the learning interest of students and motivate their initiative and enthusiasm to develop their innovative and cooperation spirit. A specific design on "PCM" of the curriculum is discussed in the paper. However, the inquiry method may be changed because of the facts of school. Therefore, exploration should be carried on continuously according to the practicalities of school including the resource of students and characteristic of curriculum.

\section{ACKNOWLEDGMENT}

This work is sponsored by the Education reform Project of Xi'an University of Science and Technology (ZX16032)

\section{REFERENCES}

[1] Ren Changsong, Inquiry learning: the self-determined construction of student knowledge [M] (In Chinese), Educational Science Publishing House, 2005.

[2] Chen Qixing, Communication Theory [M] (In Chinese), National Defense Industry Press, 2017.

[3] Mao Xinrong, Li Rong, Exploration and Practice in Inquiry Teaching of Electronic Information Professional Course [J] (In Chinese), Journal of Wuhan University (Science), 2012, 10, pp. 098-100.

[4] Chen Lin, Li Cunfu, Application of Multi Media in In Inquiry Teaching[J] (In Chinese), Information Technology, 2011,17, pp.251.

[5] Gao Jinling, Research on Inquiry Teaching[M] (In Chinese),2005,10.

[6] Shi Jiehui, Exploration on "Problem-driven" Inquiry Teaching Strategies $[\mathrm{J}]$ (In Chinese), The Guide of Science and Technology, 2011,17, pp. 129-130. 